\title{
Is speed through water a better proxy for fishing activities than speed over ground?
}

\author{
Pierre Gloaguen ${ }^{1,4, a}$, Mathieu WoILlez ${ }^{2}$, Stéphanie MAHÉvas ${ }^{1}$, Youen VERMARD ${ }^{1}$ and Etienne RIVOT ${ }^{3}$ \\ ${ }^{1}$ IFREMER, Ecologie et Modèles pour 1'Halieutique, Nantes, France \\ 2 IFREMER, Sciences et Technologies Halieutiques, Plouzané, France \\ 3 AGROCAMPUS OUEST, UMR 985 ESE Ecologie et Santé des Ecosystèmes, Rennes, France \\ ${ }^{4}$ AgroParistech/INRA, UMR MIA 518, 75231 Paris, France
}

Received 16 November 2015; Accepted 14 July 2016

\begin{abstract}
Understanding fishing vessel dynamics at a fine spatial scale is of great interest for defining appropriate spatial management plans. Different models have been developed to detect fishing activity from Vessel Monitoring System (VMS) data. While mathematical and statistical methods differ, all rely on the idea that vessel speed over ground provides information on fishing vessel activity. However, trawling with constant speed relative to the water mass may as well prove a winning strategy for both technical (to ensure sufficient trawl opening) and biological (to limit escapement of fish) reasons. Therefore, considering speed through water instead of speed over ground might provide insights into fishing activities. We developed a method combining surface currents derived from ocean circulation models with VMS data to estimate vessel speed through water. We then used vessel speed through water as input to two previously published segmentation methods to infer fishing activity during a fishing trip. We illustrate the approach by analysing trajectories of trawlers operating in the Eastern English Channel. All vessels were equipped with VMS and part of the Obsmer national discard sampling programme. Overall, results showed that surface currents influenced fishing behaviour, and trawling preferentially occured parallel to surface currents. Speed over ground associated with trawling behaviour was much more variable than speed through water, suggesting that trawling occured at constant engine regimes. However, for both segmentation methods using speed through water instead of speed over ground did not improve our capacity to identify trawling sequences. In both cases the amount of time spent trawling during a trip was overestimated.
\end{abstract}

Keywords: Vessel monitoring system / surface currents / hidden Markov models, MARS 3D, Obsmer

\section{Introduction}

Understanding fishing vessel dynamics at a fine spatial scale is of great interest for defining appropriate management measures. Fishing trips typically consist of a sequence of activities, such as steaming and trawling. For trawlers, identifying and characterising trawling sequences during a fishing trip is a key step for understanding spatio-temporal dynamics of fishing effort allocation (Vermard et al. 2010) and for characterising trawling costs when evaluating the economic performance of fisheries (Pelletier et al. 2009).

The analysis of GPS positions from Satellite-based Vessel Monitoring System (VMS) has received growing attention in the last decade (Deng et al. 2005; Hintzen et al. 2010; Lee et al. 2010; Mills et al. 2007; Rijnsdorp et al. 2011; Russo et al. 2011a,b). Various models have been developed to detect fishing activity from VMS data. While mathematical and statistical methods differ, all rely on the idea that vessel speed

\footnotetext{
a Corresponding author:

pierre.gloaguen@agroparistech.fr
}

over ground, derived from successive GPS positions, provides critical information to infer fishing activity. This idea is mainly based on the fact that at least two distinct activities are carried out during a fishing trip. The first one consists of steaming to the fishing zone (or going back to the harbor), which occurs at high speed. The second one is the actual fishing activity, it occurs at lower speed due to the use of fishing gear that slows down the vessel (see Peel and Good 2011, for instance).

To segment a fishing trip into fishing and non-fishing activities, the simplest method considers that fishing occurs when vessel speed is below a certain threshold value (Berthou et al. 2013). A more mechanistic approach is possible using Hidden Markov Models. In this approach, the sequence of activities is modelled as a Markov process (Charles et al. 2014; Gloaguen et al. 2015; Peel and Good 2011; Vermard et al. 2010; Walker and Bez 2010). These models have been shown to perform well to capture realistic sequences of fishing/non-fishing activities (Joo et al. 2013).

However, trawl efficiency might more depend on the movement of the fishing gear through water rather than relative 


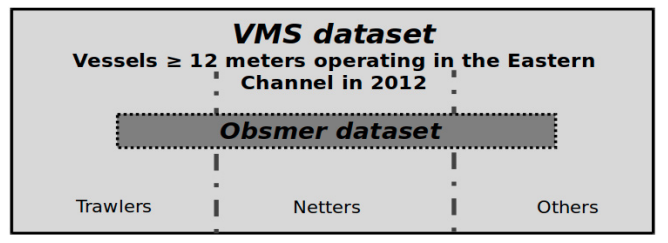

(a)

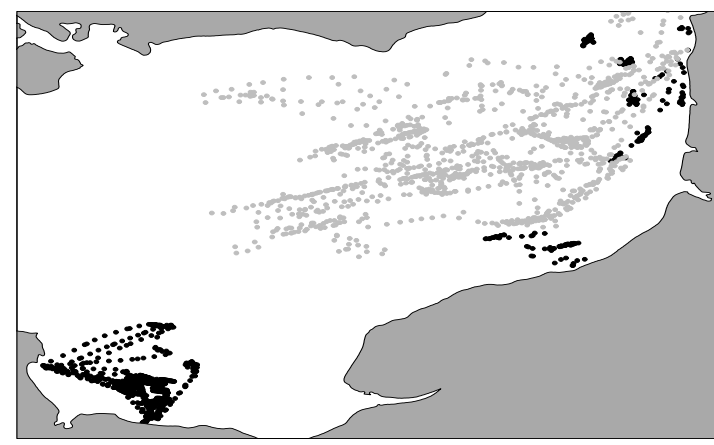

(b)

Fig. 1. (a) Structure of the VMS dataset for vessels $>12 \mathrm{~m}$ operating in the Eastern English Channel including trawlers, netters and other vessels. A subset of vessels was sampled at sea as part of the Obsmer national sampling programme symbolized by the dotted box. In 2012, among the 212 vessels in the VMS dataset, nine trawlers and nine netters were also sampled by Obsmer. (b) VMS data points for Obsmer sampled trips for trawlers (grey points) and trammel netters (black points).

to the ground. In particular, speed through water is a key feature to ensure good opening of the trawl (Fridman et al. 1986). Moreover, for some important commercial demersal fish species swimming near the sea floor, a sufficient speed through water can be needed to limit fish escapement (Rosen et al. 2012; Trenkel et al. 2004), and trawling with the current (instead of against the current) will maximise the area trawled for the same fuel consumption.

Differences between speed through water and speed over ground may not be negligible. Indeed, surface currents can be very strong in some coastal fishing areas (e.g. in the Eastern English Channel) and could decorrelate speed over ground from speed through water. Also, because surface currents are often related to tides, the correlation may fluctuate on a temporal scale that is of the same order of magnitude than the duration of fishing operations. For instance, in a recent paper, analysing trips of otter trawlers operating in the Eastern English Channel, Gloaguen et al. (2015) found speed over ground oscillated with an approximately twelve-hour period. This suggests that speed over ground could inform more on surface currents rather than the fishing activity itself.

Thus, when surface currents are strong, one might expect that trawling preferentially occurs with the current and hence speed through water might be more informative for identifying fishing activities compared to speed over ground. Indeed, this behavior might be due to fishing strategy (limiting fish escapement) or technical constraints (opening of the trawl).

Despite the potential importance of vessel speed relative to water speed for structuring trawling activities, little attention has been paid in the literature to speed through water as a key variable to infer fishing activity from GPS position records. In this paper, we develop a method combining surface currents derived from ocean circulation models with VMS data to estimate speed through water for fishing vessel trajectories. Then, using two previously published models, a simple speed threshold and a mechanistic Hidden Markov Model, we investigate whether considering speed through water instead of speed over ground improves the segmentation of trajectories into fishing and non-fishing activities. We illustrate the approach with data from fishing trips of trawlers operating in the Eastern English Channel where surface currents are known to be particularly strong, and are suspected to structure part of the fishing activity.

\section{Material and methods}

\subsection{VMS data for the French fleet in the Eastern English Channel}

VMS data from 211 French vessels ( $>12 \mathrm{~m}$ ) operating in the Eastern English Channel (ICES area VIId) in 2012 were used for this study.The data contained GPS positions recorded on average every hour. The vessels perform with different gears (grouped into trawls, nets, and others, Fig. 1) and belong to mixed fisheries, which is the majority in the Eastern Channel (Andre et al. 2009; Leblond et al. 2014). Due to confidentiality reasons the gear used was not available. However, for a subset of vessels and trips information on gear and time of fishing operations could be extracted from the data collected by the Obsmer onboard discard sampling programme (Dubé et al. 2012). In 2012, nine trawlers (12 fishing trips) and nine (trammel) netters (38 fishing trips), all equipped with VMS, were covered by the sampling programme during at least one trip. As all hauling times are known for these trips, the corresponding GPS positions in the VMS data set could be labelled as fishing or non-fishing.

\subsection{Computing speed through water}

For each trip, speed over ground was derived from the sequence of recorded GPS positions. These speeds were then combined with surface current fields derived from a hydrodynamical model to estimate speed through water. An overview of the method is given below; technical details can be found in Appendix A.

For each trip, recorded GPS positions (latitude and longitude) are denoted $\left(X_{i}\right)_{i=0 \ldots n}$ for times $t_{0} \ldots t_{n}$. From this vectorial speed over ground, denoted $\left(V_{i}^{\text {raw }}\right)_{i=0 \ldots n-1}$, was derived assuming a linear travelling path between subsequent positions. Speed over ground results from the addition of forces 


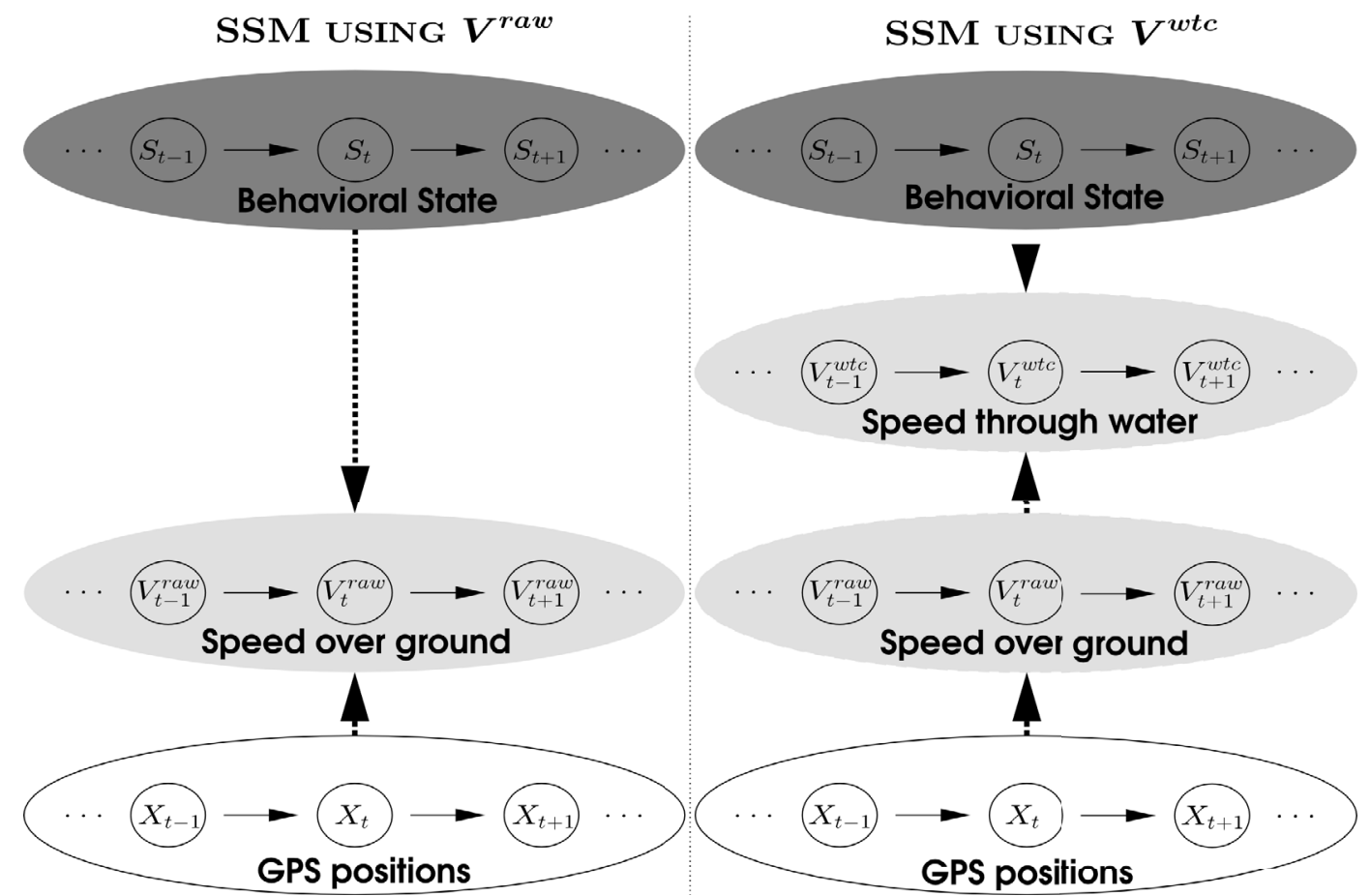

Fig. 2. Structure of state space model (SSM) used to infer fishing vessel activity. White circles are observed, grey circles are computed, and black circles are hidden and need to be estimated.

due to vessel steaming power on one hand, and surface currents on the other hand. Therefore the surface current component was removed to obtain an estimate of speed through water, hereafter denoted by $\left(V_{i}^{w t c}\right)_{i=0 \ldots n-1}$.

Surface currents were derived from outputs of the hydrodynamical simulation model MARS 3D (Lazure and Dumas 2008) which was developed to obtain operational predictions for coastal oceanography applications (Lecornu and De Roeck 2009). Because the model provided hourly surface currents on a $2.5 \mathrm{~km} \times 2.5 \mathrm{~km}$ grid, spatio-temporal interpolation was used to associate model outputs of surface currents to each recorded GPS position. The speed through water mass was then obtained by subtracting the current component from estimated speed over ground.

In addition to estimating speed through water, the surface current field was used to compute the relative direction of fishing vessels with respect to surface currents. This information then allowed us to test whether the direction of surface currents had any impact on the direction of fishing activity.

\subsection{Identifying fishing sequences from speed over ground and speed through water}

For each fishing trip also sampled by the Obsmer programme, estimated speed over ground $\left(V^{\text {raw }}\right)_{i \geq 0}$ and speed through water $\left(V^{w t c}\right)_{i \geq 0}$ were used to infer fishing activity. Two previously published models were used for this purpose. Because no new model development was done in this work, we briefly summarise the principles of the two models.

- Speed threshold (Hintzen et al. 2012). The speed threshold method considers two possible activities (or behavioural states): fishing and steaming. At each time step $i$ in the sequence $i=0, \ldots, n-1$, the vessel's activity is assumed to be fishing if $\left\|V_{i}\right\|<4.5 \mathrm{knots}$, and not-fishing otherwise.

- Hidden Markov Model (HMM). The method is a simplified version of the HMM developed by Vermard et al. (2010), and is also very close to models presented in Walker and Bez (2010) and Peel and Good (2011). The general structure of the state space model applied to fishing vessel activities is summarised in Figure 2. We only present the key principles of the approach; model details can be found in the references cited above.

The model considers two possible activities (or behavioural states): fishing and non-fishing. The sequence of hidden (unkown) activities $(S)_{i=0 \ldots n-1}$ is modeled as a homogeneous Markov chain. Vessel movement is assumed to be linear between two time steps. Movement is described by scalar speed $\left\|V_{i}\right\|$ and turning angle $\theta_{i}$. The two processes are assumed to be independent at each time step. Speed and turning angle are drawn from a Normal distribution and a wrapped Cauchy distribution respectively, with parameters depending on the hidden behaviour. The model is fitted within a Bayesian framework using MCMC simulations (OpenBUGS software).

The capacity to identify the true sequence of behaviours (fishing or non-fishing) was used to measure the performance of the two methods. At each observed position, the inferred activity was compared to the true activity as reported by the onboard observer. The misclassification rate was computed as the percentage of time steps where the activity was misidentified. This error was decomposed into its two components, false positives (inferred fishing whereas the vessel was not fishing) and false negatives (inferred non fishing while the vessel was fishing). 

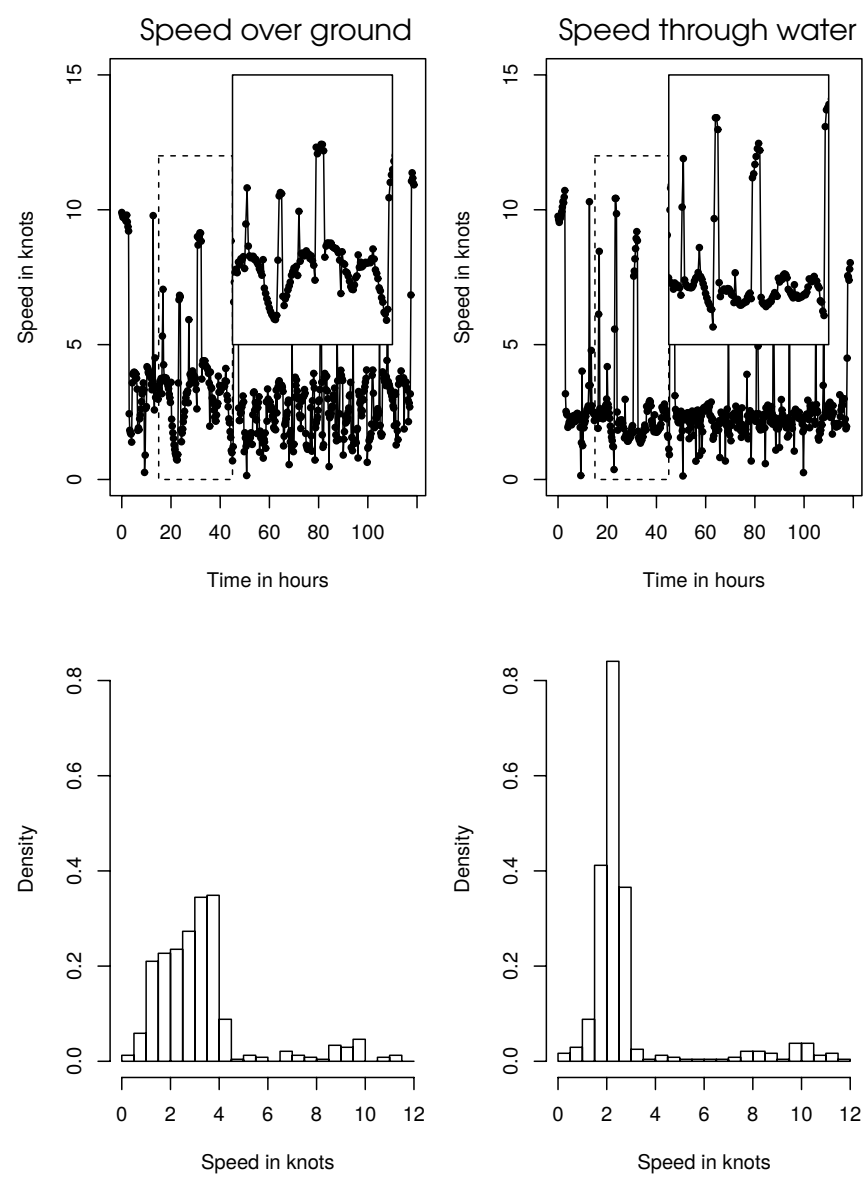

Fig. 3. Time series for speed over ground and speed through water for a fishing trip of a bottom trawler. Top line: Plots of speed processes, a focus is made on an oscillating pattern (on $\left\|V^{\text {raw }}\right\|$ ) that is flattened when surface currents are removed. Bottom line: Overall distribution of speeds for this trip.

\section{Results}

\subsection{Comparing speed through water with speed over ground}

Figure 3 shows an example of estimated speeds over ground and corresponding speeds through water. This trip was carried out by an offshore bottom trawler. For speeds below 4.5 knots, speed over ground exhibited sinusoidal variations between 2 and 4 knots, with an approximate time period of $12 \mathrm{~h}$ (Fig. 3), while those fluctuations were dampened to around 2.5 knots when considering speed through water. As a result the histogram of speeds below 4.5 knots showed a clear unique mode for speed through water, while it was more spread between 2 and 4 knots for speed over ground.

Figure 4 shows the frequency distributions of speed over ground and speed through water for all vessels in the VMS data set, i.e. all fishing gears combined. The two distributions differed significantly (Kolmogorov Smirnoff test P-value $=2 \times$ $10^{-16}$ ), though, the difference was small. However, clear differences between the two frequency distributions became visible when considering fishing gears separately using the Obsmer data set (Figs. 4b and 4c). While speed distributions did not differ for netters, the speed process of bottom trawlers seemed to have been strongly impacted by surface currents.

As for the example shown in Figure 3, speeds over ground between 2 and 4 knots corresponded to speeds through water of around 2.5 knots. Thus, speed through water was much less variable (at low speed) than speed over ground.

The relative direction of vessels with respect to the direction of surface currents was analysed for low vessel speeds (<4.5 knots) only. Rao's test for uniformity (Rao 1976) rejected the null hypothesis of uniformity, that is of all relative directions occurring with the same frequency $(\mathrm{P}$-value $=$ $2 \times 10^{-16}$, the test was performed by retaining only every fourth speed estimate to ensure independence). This indicates the existence of preferential relative vessel directions at low speed.

To investigate this further, we focused on four broad categories: relative vessel direction between 0 and $45^{\circ}$ (with surface current), between 45 and $90^{\circ}$, between 90 and $135^{\circ}$ (in the two cases the surface current is transversal) and between 135 and $180^{\circ}$ (against surface current).

For the VMS data set the proportion of vessel directions estimated to have been with or against the surface current was around $68 \%$ (see Fig. 5), indicating a preferential direction for fishing, that is parallel to surface currents (the null hypothesis of equal proportions of parallel and transversal directions was rejected based on a binomial test; P-value $<0.001)$. In the Eastern English Channel, the main currents are parallel to the coast. Therefore, hauling in this region would be more likely in this direction.

\subsection{Evaluating the influence on fishing activity identification}

The performance of the two methods to split a vessel trip between fishing and non-fishing activities was compared for speed over ground and speed through water. The comparison was made for 12 fishing trips carried out using bottom trawls, whose speeds were affected by surface currents (see Fig. 4). The misclassification rate was estimated by comparing observed behaviour (recorded by the onboard observer) with estimated behaviour (Table 1). Surprisingly, using speed through water instead of speed over ground did not improve the classification performance, neither for the threshold method nor for the HMM approach. Both methods performed similarly for this small data set. It is worth noting that the misclassification error mainly came from false positives. The overall time fishing (trawling) would therefore be overestimated in both cases.

\section{Discussion}

In this paper, we investigated the importance of considering movements of fishing vessels relative to the water mass (instead of relative to the ground) to analyse fishing activity. Because VMS data provide GPS positions, fishing vessel movements have traditionally been analysed using speed over ground which is easily computed from GPS position records. However, because of both technical (opening of the trawl) 


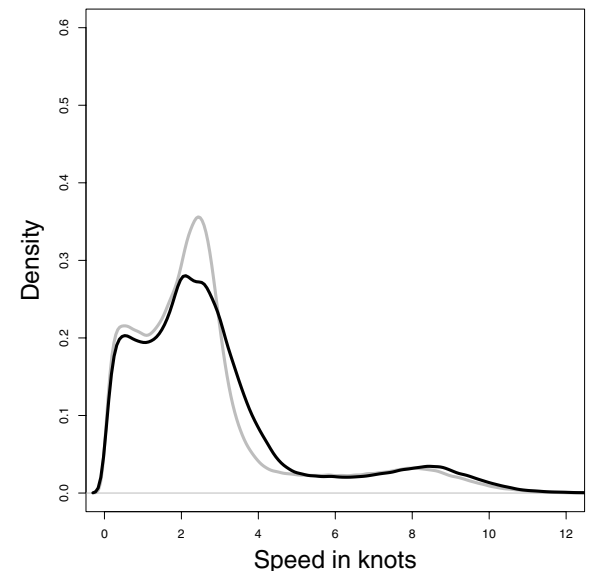

(a)

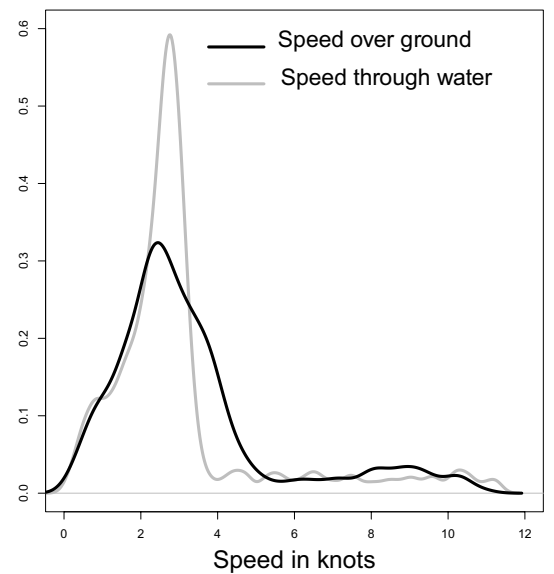

(b)

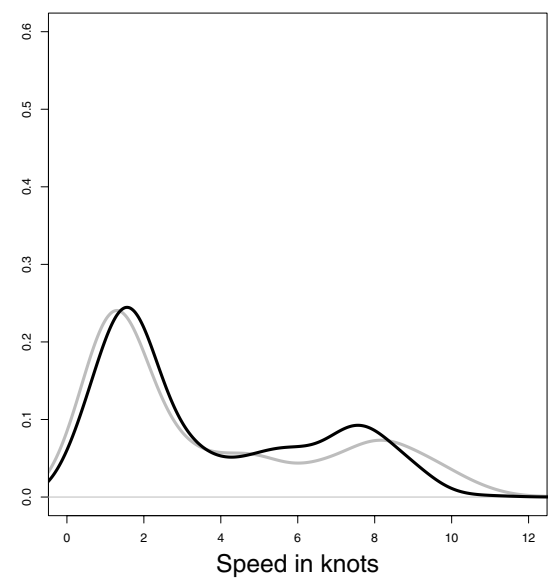

(c)

Fig. 4. Frequency distributions of speed over ground and speed through water. (a) Speed profiles for all fishing trips, all gears combined (VMS dataset). (b) Speed profiles for fishing trips performed using bottom trawls (Obsmer dataset). (c) Speed profiles for fishing trips performed using trammel nets (Obsmer dataset).

Table 1. Classification errors (\%) for identifying fishing activity for two methods and two vessel speed types. For method descriptions see text.

\begin{tabular}{ccccc} 
& \multicolumn{2}{c}{ Threshold approach } & \multicolumn{2}{c}{ HMM approach } \\
& Speed over ground & Speed throuh water & Speed over ground & Speed through water \\
\hline Error type & 13.46 & 13.87 & 13.54 & 13.70 \\
False Positive & 10.13 & 11.54 & 11.54 & 11.21 \\
False Negative & 3.32 & 2.33 & 1.99 & 2.49 \\
\hline
\end{tabular}

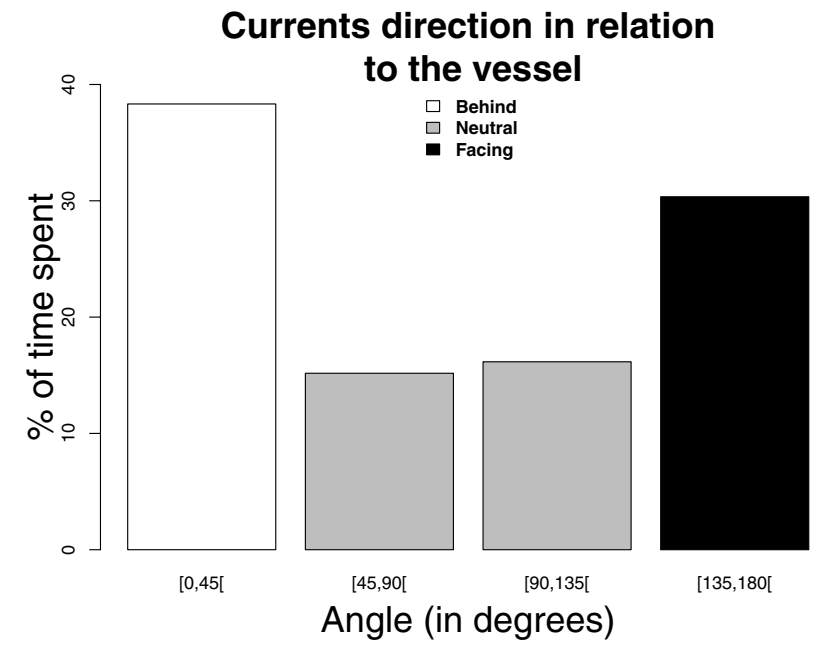

Fig. 5. Proportion of estimated relative fishing vessel directions in relation to surface currents at low vessel speed ( $<4.5$ knots). Classes from left to right: vessel moving with the surface current, vessel perpendicular to surface current (two central classes), vessel moving against surface current.

and biological (fish escapement behaviour) reasons, trawling efficiency may depend upon the relative movements of the fishing gear in relation to the water mass. Moreover, differences between speed through water and speed over ground might not be negligible in areas with strong currents (e.g. tidal currents).

The results suggested that the importance of surface currents for analysing fishing activity from VMS data might depend upon the fishing gear, with a much higher impact on speed over ground for bottom trawlers than for netters.

Looking at speed distributions, the influence of currents was only weak when considering all VMS data together, or when considering netters. However, the impact was strong when considering bottom trawlers. In this case, the lower speed over ground, likely associated with trawling sequences, varied between 2 and 4.5 knots, while the speed through water remained more constant at around 2.5 knots. This highlights the influence of surface currents on the variability of speed over ground, with speed through water remaining more constant. We can conjecture that this conclusion holds for all trawling gears whose use implies technical constraints (Fridman et al. 1986).

Moreover, the orientation of fishing vessels in relation to surface currents showed that, at low speed, vessels spent most of their time (more than 68\%) steaming with or against the current compared to perpendicular. This suggests that surface current orientations are an environmental constraint for vessels dynamics in the Eastern English Channel and should be taken into account when studying their displacements.

The results suggest that trawling activity is mainly performed in a direction parallel to the currents and at more or less 
constant engine regime, leading to a rather constant speed through water while speed over ground varies with the currents. In the case of trawling gears, the speed of the gear is then constant relative to the water mass, which may help to limit fish escapement (Trenkel et al. 2004).

In the particular case of the Eastern English Channel, because the intensity of currents increases with distance to the coast, the impact of surface currents on the observed speed histogram might have depended on vessel fishing locations. The nine trawlers used to perform this analysis tended to operate in the middle of the Channel (therefore, far from the shore), whereas netters stayed closer to the coast.

As an important result, when considering speed below 4.5 knots preferentially associated to trawling behaviour, our study revealed that speed through water was much less variable than speed over ground. An important hypothesis of HMM developed by Vermard et al. (2010), Walker and Bez (2010) and Peel and Good (2011) is the normal distribution of the speed distribution for a given behaviour. It was shown here that speed through water better supported this assumption than the usual speed over ground.

This study highlights that the presence of two modes at low speed in the raw speed histogram does not necessarily imply two different fishing behaviours (for instance, for bottom trawlers). This is a meaningful result that must be taken into account when using methods that directly rely on speed to identify fishing behaviour. However, when two modes persist after transforming to speed through water, this might imply two different fishing behaviours. In this case, the structure of the state space model used here, having only one fishing behaviour type, might be unsuitable.

Moreover, considering speed through water might be of great importance for economic analyses that balance fishing yields with exploitation costs (Beare and Machiels 2012; Daurès et al. 2013; Poos et al. 2013). Indeed, exploitation costs strongly depend upon fuel consumption. Because speed through water is a good proxy of the engine regime, it would be worth considering the use of speed through water instead of speed over ground to infer exploitation costs.

The importance of removing the effect of surface currents on vessel speed when splitting a fishing trip between fishing and non-fishing behaviour was also tested, using two different estimation methods and validation data from the Obsmer programme. However, the results showed that using speed through water did not improve classification performance. For the threshold method, the performance did not improve as both speed over ground and speed through water were below 4.5 knots. The 4.5 knots threshold is therefore suitable for the area and the strength of encountered surface currents. However, this threshold value could be set differently for areas with stronger currents. In the case of the HMM approach, which was based on the model developed by Vermard et al. (2010), classification performance was not improved either, even though the normality assumption of the speed process was less violated when considering speed through water. The HMM approach is therefore robust to this variability, and relies more on mean speed to identify each behaviour. Indeed, this mean remained the same for fishing behaviour (around 2.5 knots) for both speed measures.
Overall, considering speed through water instead of speed over ground might not be necessary for splitting trajectories into fishing and non-fishing activities, especially when it requires additional (and possibly costly) interpolation of physical model outputs. Both methods gave similar results, having a large number of false positives, and therefore overestimated the amount of time spent fishing during a trip. Further, for bottom trawlers the threshold method is simpler and was as efficient as the model based HMM approach. Moreover, in order to improve the detection of fishing activities, new methods should probably focus on decreasing false positives.

In conclusion, we suggest considering the main direction of hauling with respect to the direction of surface currents when analysing fishing vessel dynamics. Finally, results presented here suggest to use simple methods when processing VMS data rather than complex mechanistic models.

\section{Appendix A: Removing currents from vessel speed}

Here we first provide details for the method used to derive speed over ground from a sequence of recorded GPS positions and then for the method used to derive speed through water by combining the former with surface currents field.

Let us denote $\left(Z_{i}\right)_{i=1 \ldots(n)}$ the sequence of GPS positions (latitude and longitude) recorded at times $t_{1} \ldots t_{n}$. The positions are converted into a sequence of two dimensional coordinates on a regular grid, denoted $\left(X_{i}\right)_{i=1 \ldots(n)}$. The sequence of speeds over ground, denoted $\left(V_{i}^{\text {raw }}\right)_{i=1 \ldots(n-1)}$ is then derived from the sequence of positions assuming a linear path between points.

$$
V_{i}^{\text {raw }}=\frac{X_{i+1}-X_{i}}{t_{i+1}-t_{i}}
$$

Speed over ground results from the combination of forces due to the engine and surface currents. To remove the surface current component from the raw speed computed in equation (A.1), outputs of the hydrodynamical model MARS 3D were used. MARS 3D was developed by IFREMER (Lazure and Dumas 2008). Surface currents (taking wind into account) are computed hourly on a $2.5 \mathrm{~km} \times 2.5 \mathrm{~km}$ grid. The model provides the vector of surface current (vector) $C_{h}^{P}$ at each point $P$ of the grid and every hour $h$ of the day. The time steps of GPS positions $\left(X_{i}\right)_{i=1 \ldots(n)}$ do not match the time step and the grid of MARS 3D outputs. Each observed position $X_{i}$ is recorded at time $t_{i}=h_{i}: m_{i}$ (hour:minute) and is linked to its closest point $M$ in the model's grid. To compute an estimate of the current at position $X_{i}$ and time $t_{i}$ (noted $\hat{C}_{t_{i}}^{X_{i}}$ ), interpolation is performed following the equation

$$
\hat{C}_{t_{i}}^{X_{i}}=\left(1-\frac{m_{i}}{60}\right) C_{h_{i}}^{M}+\frac{m_{i}}{60} C_{h_{i}+1}^{M}
$$

Combining surface currents $\hat{C}_{t_{i}}^{X_{i}}$ in (A.2) with speed over ground in equation (A.1), speed through water, denoted $V^{w t c}$, is computed as:

$$
V_{i}^{w t c}=V^{\text {raw }}-<\frac{V^{\text {raw }}}{\left\|V^{\text {raw }}\right\|} ; \hat{C}_{t_{i}}^{X_{i}}>\frac{V^{\text {raw }}}{\left\|V^{\text {raw }}\right\|}
$$




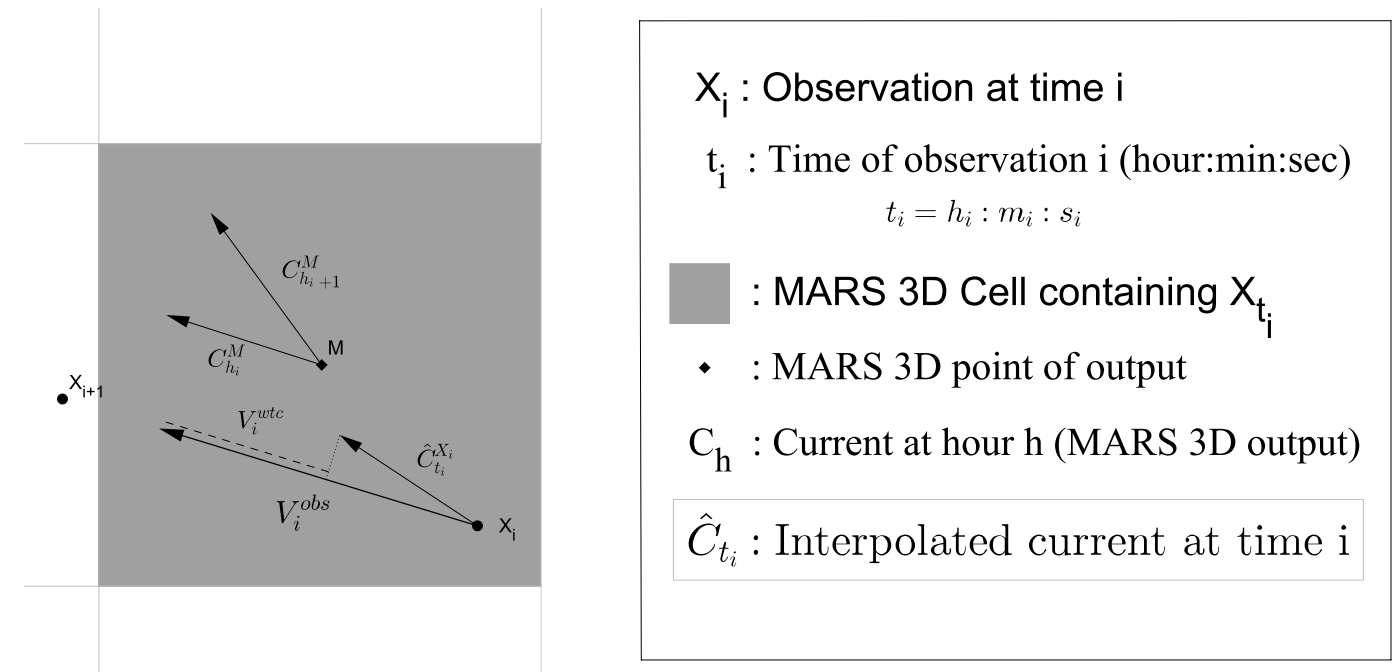

Fig. A1. Method to remove surface currents from velocity process to obtain vessel speed through water.

where $<\cdot ; \cdot>$ is the usual scalar product. A geometric representation of equation (A.3) is given in Figure A1.

Using equation (A.1), the $1 \mathrm{D}$ speed process $\left\|V_{i}^{\text {raw }}\right\|$ can be computed.

\section{References}

Andre C., Franck C., Lucie C., Jean-Claude D., Juliette D., JeanMarie D., Ludovic D., Aurélie F., Clément G., Laure G., Stuart H., Roger J., Philippe K., Valentina L., Corinne M., Geoff M., Jocelyne M., Yoshi O., Emilie R., Bob S., Nicolas S., Sandrine V., Ching-Maria V., Yves V., Joanne W., Caroline W., 2009, Atlas des Habitats des Ressources Marines de la Manche Orientale CHARM II.

Beare D., Machiels M., 2012, Beam trawlermen take feet off gas in response to oil price hikes. ICES J. Mar. Sci., DOI: 10.1093/ icesjms/fss057.

Berthou P., Bégot E., Laurans M., Campéas A., Leblond E., Habasque J., 2013, Présentation de la suite logicielle AlgoPesca. Rapport interne Ifremer.

Charles C., Gillis D., Wade E., 2014, Using hidden markov models to infer vessel activities in the snow crab (chionoecetes opilio) fixed gear fishery and their application to catch standardization. Canadian J. Fish. Aquat. Sci. 71, 1817-1829.

Daurès F., Trenkel V.M., Guyader O., 2013, Modelling the fishing costs of french commercial vessels in the bay of biscay. Fisheries Research 146, 74-85.

Deng R., Dichmont C., Milton D., Haywood M., Vance D., Hall N., Die D., 2005, Can vessel monitoring system data also be used to study trawling intensity and population depletion? the example of australia's northern prawn fishery. Canadian J. Fish. Aquat. Sci. $62,611-622$.

Dubé B., Diméet J., Rochet M.J., Tétard A., Gaudou O., Messanot C., Biseau A., Salaün M., 2012, Observations à bord des navires de pêche professionnelle. bilan de l'échantillonnage 2011.

Fridman A.L., Carrothers P., et al., 1986, Calculations for fishing gear designs. Fishing news books England.
Gloaguen P., Mahévas S., Rivot E., Woillez M., Guitton J., Vermard Y., Etienne M.P., 2015, An autoregressive model to describe fishing vessel movement and activity. Environmetrics 26, 17-28.

Hintzen N.T., Bastardie F., Beare D., Piet G.J., Ulrich C., Deporte N., Egekvist J., Degel H., 2012, VMStools: Open-source software for the processing, analysis and visualisation of fisheries logbook and VMS data. Fisheries Research 115, 31-43.

Hintzen N.T., Piet G.J., Brunel T., 2010, Improved estimation of trawling tracks using cubic Hermite spline interpolation of position registration data. Fisheries Research 101, 108-115.

Joo R., Bertrand S., Tam J., Fablet R., 2013, Hidden markov models: The best models for forager movements? Plos One 8.

Lazure P., Dumas F., 2008, An external-internal mode coupling for a 3D hydrodynamical model for applications at regional scale (MARS). Adv. Water Resour. 31, 233-250.

Leblond E., Daures F., Leonardi S., Demaneche S., Merrien C., Berthou P., Rostiaux E., Macher C., Lespagnol P., Le Grand C., Le Blond S., 2014, Synthèse des flottilles de pêche 2012, Flotte de Mer du Nord - Manche - Atlantique. Flotte de Méditerranée. http://archimer.ifremer.fr/doc/00248/35971/.

Lecornu F., De Roeck Y.H., 2009, Previmer - observations et prévisions côtières. La Houille Blanche 0, 60-63.

Lee J., South A.B., Jennings S., 2010, Developing reliable, repeatable, and accessible methods to provide high-resolution estimates of fishing-effort distributions from vessel monitoring system (VMS) data. ICES J. Mar. Sci. 67, 1260-1271.

Mills C.M., Townsend S.E., Jennings S., Eastwood P.D., Houghton C.A., 2007, Estimating high resolution trawl fishing effort from satellite-based vessel monitoring system data. ICES J. Mar. Sci. 64, 248-255.

Peel D., Good N.M., 2011, A hidden markov model approach for determining vessel activity from vessel monitoring system data. Canadian J. Fish. Aquat. Sci. 68, 1252-1264.

Pelletier D., Mahevas S., drouineau H., Vermard Y., Thebaud O., Guyader O., Poussind B., 2009, Evaluation of the bioeconomic sustainability of multi-species multi-fleet fisheries under a wide range of policy options using isis-fish. Ecol. Modelling 220, 1013-1033. 
Poos J.J., Turenhout M.N., van Oostenbrugge H.A., Rijnsdorp A.D., 2013, Adaptive response of beam trawl fishers to rising fuel cost. ICES J. Mar. Sci. 70(3), 675-684.

Rao J., 1976, Some tests based on arc-lengths for the circle. Sankhyā: The Indian Journal of Statistics, Series B, 329-338.

Rijnsdorp A.D., Poos J.J., Quirijns F.J., 2011, Spatial dimension and exploitation dynamics of local fishing grounds by fishers targeting several flatfish species. Canadian J. Fish. Aquat. Sci. 68, 1064-1076.

Rosen S., Engås A., Fernö A., Jörgensen T., 2012, The reactions of shoaling adult cod to a pelagic trawl: implications for commercial trawling. ICES J. Mar. Sci.

Russo T., Parisi A., Cataudella S., 2011a, New insights in interpolating fishing tracks from VMS data for different metiers. Fisheries Research 108, 184-194.
Russo T., Parisi A., Prorgi M., Boccoli F., Cignini I., Tordoni M., Cataudella S., 2011b, When behaviour reveals activity: Assigning fishing effort to métiers based on VMS data using artificial neural networks. Fisheries Research 111, 53-64.

Trenkel V., Lorance P., Mahévas S., 2004, Do visual transects provide true population density estimates for deepwater fish? ICES J. Mar. Sci. 61, 1050-1056.

Vermard Y., Rivot E., Mahevas S., Marchal P., Gascuel D., 2010, Identifying fishing trip behaviour and estimating fishing effort from VMS data using bayesian hidden markov models. Ecol. Modelling 221, 1757-1769.

Walker E., Bez N., 2010, A pioneer validation of a state-space model of vessel trajectories (VMS) with observers' data. Ecol. Modelling 221, 2008-2017. 